\title{
Determination of rhodium content by the method of Stripping voltammetry in ores and technogenic raw materials
}

\author{
N.A. Kolpakova ${ }^{1}$, E.N. Dyachenko ${ }^{1}$ \\ ${ }^{1}$ Federal State autonomous educational institution of higher education "National Research Tomsk \\ Polytechnic University, Russia
}

\begin{abstract}
The method of determination of rhodium by the method of Stripping voltammetry in ores and technogenic raw materials has been developed. Determination of rhodium (III) in solution by Stripping voltammetry method was carried out by peak of selective electrooxidation of bismuth from intermetallic compound Bi2Rh. $1 \mathrm{M} \mathrm{KSCN}$ was selected as a background electrolyte. The method of melting of the sample with potassium tetrafluoroborate $(\mathrm{KBrF} 4)$ at a temperature of 500 was used for the conversion of the rhodium solution. The method of deposition of most ions present in solution of alkali metals was used to separate ions of rhodium (III) from the matrix of the samples. Ions of $\mathrm{Pt}$ (IV), Rh (III) and Ir (IV) remain in solution after precipitation. Ions of iridium (IV) and 10fold excess of platinum (IV) do not interfere with the determination of rhodium (III) against the background of $1 \mathrm{M} \mathrm{KSCN}$.
\end{abstract}

\section{Introduction}

The biggest obstacle to the research of potential natural sources of platinum group metals is extremely poorly developed base of analytical methods for their quantification. The content of rhodium in the technogenic raw materials ranges from $0.001 \mathrm{mg} / \mathrm{kg}$ to $10 \mathrm{mg} / \mathrm{kg}$. Advanced instrumental methods of analysis are necessary to determine such low rhodium content. Papers [1-4] show the capabilities of different analysis methods in determining the rhodium in mineral raw materials. As these papers show all existing methods of analysis require effective methods of sample decomposition and methods for separation of rhodium from the sample matrix.

We propose a method of stripping voltammetry (SV) as a method of analysis for determination of rhodium in mineral raw materials. This method is a highly sensitive instrumental method of analysis, which allows determining the elements after their concentration at the electrode surface, followed by sediment electrooxidation. However, determination of rhodium using this method can cause certain difficulties. We cannot detect the process of electroreduction of rhodium ions (III) in the graphite electrode (GE) on the current-voltage curves. It is connected with hydrogen evolution catalytic process that flows in parallel and results in an overlap of rhodium (III) ions electroreduction process. The process of electrooxidation of rhodium precipitate occurs at potentials greater than $1 \mathrm{~V}$ and is overlapped by the process of oxygen evolution from water.

Determination of rhodium (III) ions using SV method is carried out by rhodium IV electrodeposition together with a less noble metal (activator), followed by selective electrooxidation of metal activator. The literature describes methods for SV-determining of rhodium (III) by peaks of selective electrooxidation of bismuth or mercury form intermetallic mercury-rhodium [3] and bismuth-mercury [4] compounds (IMC).

${ }^{1}$ Corresponding author: nak@tpu.ru 
The aim of this work was to develop a methodology for determination of rhodium in the gold mining mineral raw materials by stripping voltammetry by the peak of the selective electrooxidation of rhodium from intermetallic compound with bismuth and carry out determination of rhodium in a number of non-traditional gold-platinoid minefields.

\section{Material and Methods of Research}

The research is carried out using voltammetric analyzer TA-4 (LLC Research and Production Enterprise "TomAnalyt", Tomsk), complete with a personal computer. Quartz cups having volume o of $20 \mathrm{~cm}^{3}$ were used as electrolyzer. All studies were carried out in a three-electrode cell. Graphite electrode (GE) impregnated with polyethylene served as the indicator electrode, silver chloride electrode filled with saturated $\mathrm{KCl}$ solution served as the reference electrode and platinum electrode served as the auxiliary one. The studies were conducted on the backgrounds of $1 \mathrm{M} \mathrm{HCl}$ and $1 \mathrm{M} \mathrm{KSCN}$. Electrodeposition of binary electrolytic precipitation was carried out from solutions containing ions of bismuth (III) and rhodium (III). Electrochemical cleaning of the electrode surface was carried out in the background electrolyte within one minute at a potential of $1.2 \mathrm{~V}$ or mechanically rubbing the electrode with the filter paper. The surface of the electrode was renewed after each measurement. The solution was stirred automatically during electrolysis by vibrating the working electrode as conditioned by analyzer. All studies were performed using reagents with qualification not lower than "chemically pure" under normal conditions.

\section{Results and discussion}

Selecting the background electrolyte. Rhodium was introduced into the test solution in the form of chloride complexes. $\mathrm{RhCl}_{6}^{3-}$. In acid background electrolytes bismuth is present in solution in the form of aquacomplexes $\left[\mathrm{Bi}\left(\mathrm{H}_{2} \mathrm{O}\right)_{n}\right]^{3+}$.

Electrodeposition of binary precipitate bismuth-rhodium was carried out from $1 \mathrm{M} \mathrm{HCl}$ solution containing ions of bismuth (III) and rhodium (III), at a potential of $-0.8 \mathrm{~V}$. The characteristic current-voltage curves of selective electrooxidation of bismuth from binary electrolytic precipitate bismuth-rhodium from graphite surface c electrode are shown in Fig. 1.

We observe several peaks on the current-voltage curve of precipitate electrooxidation. The peak at a potential of $-0.05 \mathrm{~V}$ corresponds to a process of electrooxidation of bismuth deposited on the surface of GE. When rhodium content in the precipitate increases the peak current of bismuth electrooxidation decreases as bismuth is bound with rhodium in IMC. Selective electrooxidation of bismuth from IMC with rhodium in the solution $1 \mathrm{M} \mathrm{HCl}$ occurs at a potential of $0.1 \mathrm{~V}$ and has a wave form. It is difficult to estimate the content of rhodium (III) by current of this wave because it overlaps the process of electrochemical oxidation of oxygen adsorbed on the rhodium. According to the literature review data [5], peak at a potential of $+0.5 \mathrm{~V}$ is the peak of oxygen electrooxidation adsorbed on rhodium.

Background $1 \mathrm{M} \mathrm{KSCN}$ has been studied in order to fix a clearer analytical signal of the process of selective electrooxidation of bismuth from IMS with rhodium. 


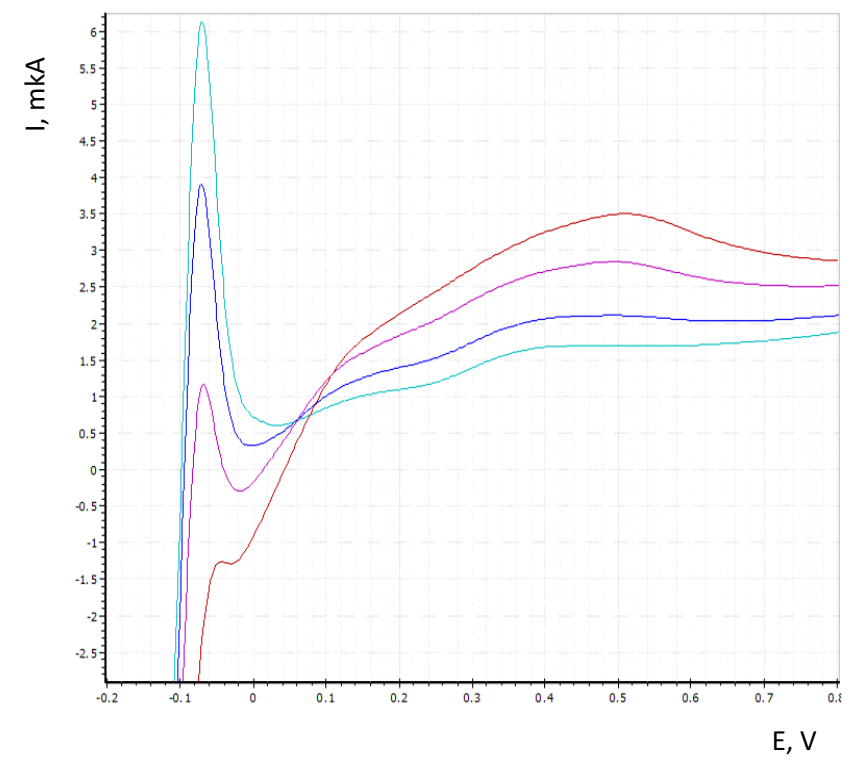

Figure 1. The current-voltage curves of the electrochemical oxidation of precipitate bismuth-rhodium surface from GE. The experimental conditions: background $1 \mathrm{M} \mathrm{HCl}$, electrolysis potential is minus $0.8 \mathrm{~V}$, electrolysis time is $\tau_{\ni}=120 \mathrm{~s}$, scanning speed $\left.\mathrm{v}=80 \mathrm{mV} / \mathrm{s}, C_{\mathrm{Bi}^{3+}}=2 \mathrm{mg} / \mathrm{l} ; 1\right) C_{\mathrm{Rh}^{3+}}=0,02 \mathrm{mg} / \mathrm{l}$; 2) $\left.C_{\mathrm{Rh}^{3+}}=0,04 \mathrm{mg} / \mathrm{l} ; 3\right) C_{\mathrm{Rh}^{3+}}=$ $0,06 \mathrm{mg} / \mathrm{l}$; 4) $C_{\mathrm{Rh}^{3+}}=0,08 \mathrm{mg} / 1$.

Typical current-voltage curves of electrochemical oxidation of binary electrolytic precipitation bismuth-rhodium from the surface of graphite electrode deposited from a solution 1M of KSCN are shown in Fig. 2.

The peak at a potential of $-0.1 \mathrm{~V}$ on the voltage-current curve corresponds to the process of electrooxidation of hydrogen adsorbed on the rhodium. This peak is well described in the literature [5]. The peak at a potential of $-0.01 \mathrm{~V}$ corresponds to the process of electrooxidation of bismuth deposited on the surface of the GE. The peak at a potential of $0.23 \mathrm{~V}$ corresponds to the selective electrooxidation of bismuth from IMS with rhodium having composition RhBi2 [4]. This peak current value is used to determine the content of rhodium (III) in solutions using stripping voltammetry method. 


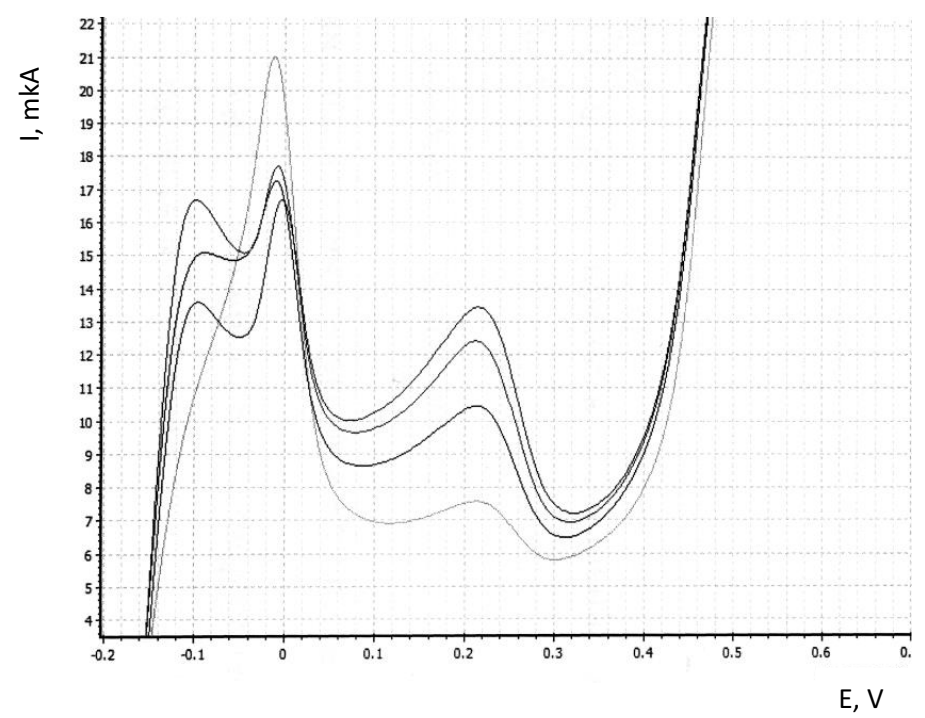

Figure 2. The current-voltage curves of the electrochemical oxidation of precipitate bismuth-rhodium surface from GE. The experimental conditions: background $1 \mathrm{M} \mathrm{KSCN}$, electrolysis potential is minus $0.8 \mathrm{~V}$, electrolysis time is $\tau_{3}=120 \mathrm{~s}$, scanning speed $\mathrm{v}=80 \mathrm{mV} /, C_{\mathrm{Bi}^{3+}}=2 \mathrm{mg} / \mathrm{l}$; 1) $C_{\mathrm{Rh}^{3+}}=0,02 \mathrm{mg} / \mathrm{l}$; 2) $C_{\mathrm{Rh}^{3+}}=0,04 \mathrm{mg} / \mathrm{l}$; 3) $C_{\mathrm{Rh}^{3+}}=$ $0,06 \mathrm{mg} / \mathrm{l}$; 4) $C_{\mathrm{Rh}^{3+}}=0,08 \mathrm{mg} / \mathrm{l}$.

Figure 3 shows the current of selective electrooxidation of bismuth $\mathrm{Bi}_{2} \mathrm{Rh}$ from IMS depending on the content of rhodium (III) in solution at a constant concentration of bismuth ions (III) in the sample solution.

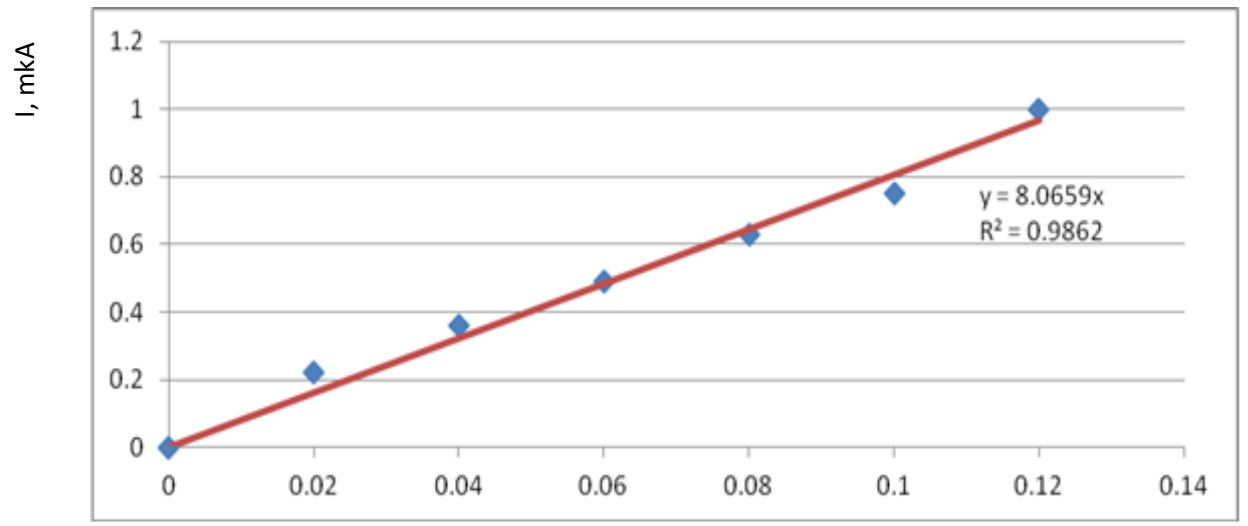

$\mathrm{C}, \mathrm{mg} / \mathrm{l}$

Figure 3. Dependence of peak current of selective electrooxidation of bismuth on rhodium ions (III) concentration in the sample solution. The experimental conditions: background $1 \mathrm{M} \mathrm{KSCN}$, electrolysis potential is minus $0.8 \mathrm{~V}$, electrolysis time is $\tau_{9}=120 \mathrm{~s}$, scanning speed $\mathrm{v}=80 \mathrm{mV} / \mathrm{s} ., C_{\mathrm{Bi}^{3+}}=2 \mathrm{mg} / \mathrm{l}$. 
Determination of rhodium in the mineral raw materials. A weighed portion of analyzed sample to be analyzed weighing $1 \mathrm{~g}$ was placed in a corundum crucible and calcined in a muffle furnace at $\mathrm{t}=700 \mathrm{C}$ for one hour. Cooled sample was mixed with five eight-fold amount (by weight) of potassium tetrafluoroborate $(\mathrm{KBrF} 4)$ directly in a crucible to decompose and coated on top uniformly by two-fold (with respect to the weight of sample) amount of $\mathrm{KBrF}_{4}$. The crucible was capped and placed in muffle electric furnace heated to $500 \mathrm{C}$. for 1.5-2.0 hours. Potassium tetrafluoroborate was taken with excess against stoichiometric reactions not only to ensure complete oxidation of the sample, but also to form a flux in which fluorocomplexes of noble metals "dissolve". After completion of decomposition process, the product was mostly in a form of pale yellow melt. The solution was evaporated on electric heater to wet salts, then dissolved in $1 \mathrm{M} \mathrm{HCl}$ and heated again for 15 minutes. Here all platinum metals pass from sample into solution in the form of chloride complexes. The resulting solution was filtered through a "blue tape" filter. After filtration, the filter was washed with bidistilled water. The resulting solution was treated with $3 \% \mathrm{NaOH}$ solution to form a precipitate of metal hydroxides. The resulting metal hydroxides were separated from the solution by filtration through a "blue tape" filter. Ions of Pt (IV), Rh (III) and Ir (IV) stay in the solution after precipitation of the hydroxides. The solution was evaporated to wet salts, dissolved in $10 \mathrm{ml}$ of $1 \mathrm{M} \mathrm{KSCN}$ and polarographised. Iridium in any ratio with rhodium does not interfere with determination of rhodium (III) on the background of $1 \mathrm{M} \mathrm{KSCN}$, because it is not able to settle on the electrode surface. According to literature review data, platinum and rhodium precipitate is a solid solution of these metals. By increasing the platinum content in electrolytic precipitate, the current of selective electrooxidation of bismuth increases, but the proportionality of current to rhodium (III) ion content remains to a tenfold excess of platinum (IV) ions in the solution.

Performance accuracy of methods of determination of rhodium was evaluated by comparing the results of IV-determination of rhodium in the standard samples of composition (SS).

Table 1. Average values of rhodium content in standard samples obtained by stripping voltammetry method (g/t, ppm, 10-4\%)

\begin{tabular}{|c|c|c|c|}
\hline \multirow{2}{*}{ Sample } & \multirow{2}{*}{$\begin{array}{c}\text { Standard sample } \\
\text { characteristics }\end{array}$} & \multicolumn{2}{|c|}{ Rhodium content, g/t } \\
\cline { 3 - 4 } & IV method & In SS \\
\hline G-3 & $\begin{array}{c}\text { Copper-nickel } \\
\text { sulfide ore }\end{array}$ & $0,64 \pm 0,03$ & 0,66 \\
\hline ST-1 & $\begin{array}{c}\text { Concentrations } \\
\text { tailings of copper } \\
\text { nickel sulphide ore }\end{array}$ & $0,095 \pm 0,024$ & 0,094 \\
\hline ShT-1 & $\begin{array}{c}\text { Matte of ore-heating } \\
\text { smelting }\end{array}$ & $3,68 \pm 0,024$ & 3,72 \\
\hline
\end{tabular}

Table 2 shows data on the content of rhodium in the quartz-gold-sulfide ore and flotation concentrate of this ore obtained by stripping voltammetry method. 
Table 2. Average values of the content of precious metals in standard samples

\begin{tabular}{|c|c|c|}
\hline \multirow{2}{*}{ Sample characteristic } & \multicolumn{2}{|c|}{ Rhodium content, $\mathrm{g} / \mathrm{t}$} \\
\cline { 2 - 3 } & IV-method & \multicolumn{2}{|c|}{ AAS method } \\
\hline Quartz-gold-sulfide ore & $0,007 \pm 0,002$ & $0,009 \pm 0,003$ \\
\hline $\begin{array}{c}\text { Flotation concentrate of } \\
\text { quartz-gold-sulfide ore }\end{array}$ & $0,065 \pm 0,008$ & $0,072 \pm 0,006$ \\
\hline
\end{tabular}

\section{Conclusions}

1. The method of determination of rhodium by stripping voltammetry in ores and technogenic raw materials was developed. Determination of rhodium (III) in solution by stripping voltammetry was carried out by the peak of selective electrooxidation of bismuth from intermetallic compound Bi2Rh. Electrolyte $1 \mathrm{M} \mathrm{KSCN}$ was selected as background.

2. The method of melting of the sample under analysis with potassium tetrafluoroborate (KBrF4) at a temperature $500{ }^{\circ} \mathrm{C}$ was used to convert rhodium into solution.

3. Method of precipitation of ions of majority metals in the solution by alkali was used for the separation of rhodium (III) ions from the sample matrix. Ions Pt (IV), Rh (III) and Ir (IV) stay in the solution after precipitation.

4. Ions of iridium (IV) and 10-fold exceed of platinum (IV) do not interfere with rhodium (III) determination against $1 \mathrm{M} \mathrm{KSCN}$ background.

\section{References}

1. Torgov V.G., Korda T.M., Demidova M.G., Gus'kova E.A., Bukhbinder G.L. ICP AES determination of platinum group elements and gold in collective extract and 21 strip product solution in analysis of geological samples // J. Anal. At. Spectrom. - 2009. - V. 24. - P. 1551-1557.

2. Arabova Z. M., Dedkov Yu. M., Arabs M. sh., Krigman L. V. Methods for the determination of rhodium (review) //Zavodskaya laboratoriya. Diagnostics of materials. - 2014. T. 80, № 8. C. 5-16.

3. Kolpakova N. A. Determination of the platinum metals in minerals by method of Stripping voltammetry (review). - 2014 - T. 80 - №. 9. - P. 5-13. 
4. Dyachenko E. N., Kolpakova N. And. Method of determination of rhodium (III) in water solutions by method of Stripping voltammetry by peak of selective electrooxidation of bismuth from intermetallic compounds with the rhodium //Abstracts of IX all-Russian conference on electrochemical methods of analysis with international participation and youth scientific school. Ekaterinburg: 29 may-3 June 2016. P. 57.

5. Mansurov, G. N., Petrov O. A. the electrochemistry of thin metal films. Monograph. -M.: MGOU, 2011. $-351 \mathrm{p}$.

6. Beamish, F. Analytical chemistry of noble metals. M: Peace. 1969,part 1. 297 p. 